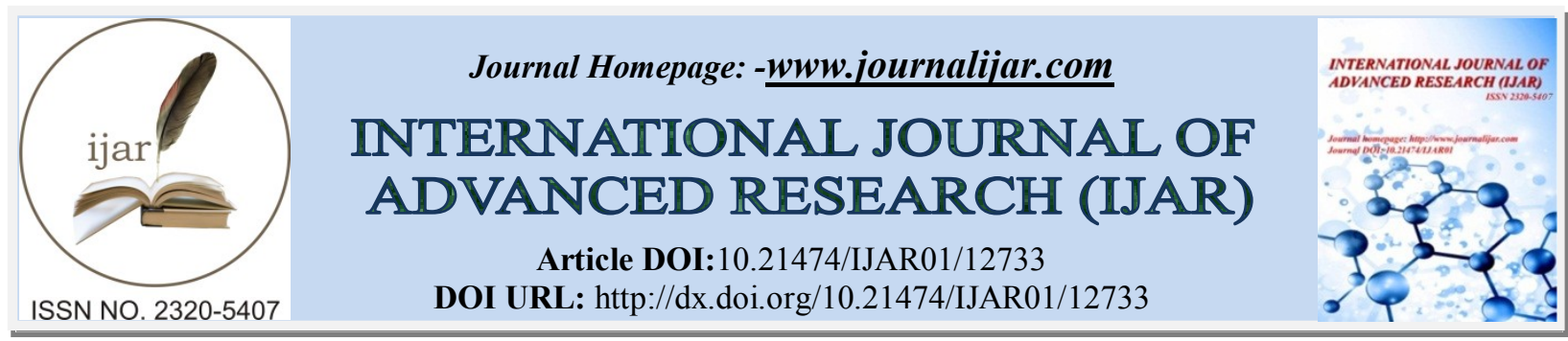

RESEARCH ARTICLE

\title{
IMPACT OF CORONAVIRUS ON DEVELOPING COUNTRIES
}

\section{Manish $\mathbf{N}^{1}$, Kumar Abhay Narayan Singh ${ }^{1}$, Yash Mehta ${ }^{1}$ and Abhishek Venkteshwar ${ }^{2}$}

1. Student, BBA Entrepreneurship, World of Work-Jain (Deemed to be) University - Center for Management Studies, India.

2. Assistant Professor and Course Facilitator Jain (Deemed to be) University - Center for Management Studies, India.

\section{Manuscript Info}

Manuscript History

Received: 10 February 2021

Final Accepted: 16 March 2021

Published: April 2021

Key words:-

Coronavirus, Developing Countries, Economy, Infrastructure, Developed Countries

\section{Abstract}

Aim: To research on the impact and implications of coronavirus on developing countries

Background: Coronavirus has affected the entire world causing disruption in the growth of many countries. The countries which have been critically affected are the developing countries. It is important for us to study the impact of coronavirus on developing countries as it would help us understand the vulnerabilities a country possessed. The developing countries could use this knowledge to prepare themselves in case of another event of this magnitude.

Design: Research paper

Data sources: A search of published evidence from 1990-2020 using key words(as outlined below) was undertaken from which relevant sources were selected tobuild an informed discussion.

Implications for developing countries: Understanding the extent of the impact would help developing countries create better systems to adapt to the challenges of the future.

Conclusion: This paper discusses the impact of coronavirus on developing countries. The virus has caused significant degradation of growth and has shaken the foundations of many countries. Developing countries are critically challenged as they do not possess the right infrastructure in health care or technology to cope with it.

Copy Right, IJAR, 2021,. All rights reserved.

\section{Introduction:-}

A novel coronavirus (CoV) named '2019-nCoV' or '2019 novel coronavirus' or 'COVID-19' by the World Health Organization (WHO) is in charge of the current outbreak of pneumonia that began at the beginning of December 2019 near in Wuhan City, Hubei Province, China [1-4]. COVID-19 is a pathogenic virus. From the phylogenetic analysis carried out with obtainable full genome sequences, bats occur to be the COVID-19 virus reservoir, but the intermediate host(s) has not been detected till now. Though three major areas of work already are ongoing in China to advise our awareness of the pathogenic origin of the outbreak. These include early inquiries of cases with symptoms occurring near in Wuhan during December 2019, ecological sampling from the Huanan Wholesale Seafood Market as well as other area markets, and the collection of detailed reports of the point of origin and type of wildlife species marketed on the Huanan market and the destination of those animals after the market has been closed 
Developing countries are, in general, countries that have not achieved a significant degree of industrialization relative to their populations, and have, in most cases, a medium to low standard of living. There is an association between low income and high population growth.

Developing countries tend to be poorer, working to become more advanced economically and socially-their infrastructures aren't as established as those you find in Europe and the US. They also rely on primary sector rolesall activities that consist of exploiting natural resources, like agriculture, mining, and forestry - and so they are particularly impacted by disrupted supply chains and lower demand for their goods. The COVID-19 pandemic has generated far-reaching impacts on the global economy with International Monetary Fund (IMF) Managing Director Kristalina Georgieva declaring the crisis "the worst economic fallout since the Great Depression." The global economy is expected to shrink by 4.4 percent. While a softer decline than the 4.9 percent forecasted in July, 2020, the pandemic's global economic cost over the next two years could reach $\$ 11$ trillion - larger than the combined economies of Japan and Germany - causing more economic devastation than the 2008 financial crisis.

\section{Review Of Literature:-}

1)The coronavirus disease (COVID-19) has critically impacted global health systems and economies, especially in developing countries. Those countries have been struggling to address the pre-existing burden of diseases with limited resources, which will become even more challenging during COVID-19. The economic implications related to COVID-19 in those countries include a high cost of care, market failures in pluralistic health systems, high outof-pocket expenses, the added burden of noncommunicable diseases, missed economic opportunities, and socioeconomic consequences like unemployment and poverty. It is essential to assess the prevalent gaps, mobilize resources, strengthen health systems financing and leadership, enhance research capacities informing evidencebased policymaking, and foster effective partnerships for addressing health and economic disparities due to COVID19.

Rodela, T. T(2020)

2) Presence of comorbidities in patients with Coronavirus disease 2019 (COVID-19) have often been associated with increased in-hospital complications and mortality. Intriguingly, several developed countries with a higher quality of life have relatively higher mortality with COVID-19, compared to the middle- or low-income countries. Moreover, certain ethnic groups have shown a higher predilection to contract COVID-19, with heightened mortality. We sought to review the available literature with regards to impact of COVID-19 and comorbidities on the health and economics, especially in context to the developing countries including India.

Awadhesh Kumar Singh, AnoopMisra (2020)

3) COVID-19 is spreading through the developing world. Many low- and middle-income countries are now reporting growing numbers of cases and imposing rigorous lockdown regulations in response, which impact all aspects of the economy. How will COVID-19 affect food-supply chains (FSCs) in developing countries? The evidence suggests that the impacts will be felt widely, but unevenly. Farm operations may be spared the worst, while small and medium-sized enterprises (SMEs) in urban areas will face significant problems. Governments will have to develop policies to respond to these varied impacts to avoid supply chain disruptions, higher food prices, and severe economic fallout for millions of employees. Thomas Reardon (2020)

4)With COVID-19 now spreading in developing countries, massive consequences on health and livelihoods are feared. Food security is the most important and crucial aspect of sustainable development. The agricultural sector forms the backbone of the economy and provides livelihood to a large section in developing countries. Therefore, the disruption in food security and the agricultural sector will have far-reaching impacts on these countries. Owing to the importance of these sectors, this paper performs a comprehensive assessment of the effect of COVID-19 on food security and agriculture. The research suggests coping and mitigation mechanisms that can be adopted to sustain livelihoods. EndashawWorkie(2020)

5)

This paper quantitatively analyzes how policy responses to the COVID-19 pandemic should differ in developing countries. To do so we build an incomplete-markets macroeconomic model with heterogeneous agents and epidemiological dynamics that features several of the key distinctions between advanced and developing economies germane to the pandemic. We focus in particular on differences in: age structure, fiscal capacity, healthcare capacity, informality, and the frequency of contacts between individuals at home, work, school and other locations. 
The model predicts that blanket lockdowns are less effective in developing countries, saving fewer lives per unit of lost GDP. In contrast, age-specific policies are even more effective, since they focus scarce public funds on shielding the smaller population of older individuals. School closures are also more effective at saving lives in developing countries, providing a greater reduction in secondary transmissions between children and older adults at home.Titan M Alon (2020)

6) The world is experiencing the worst pandemic crisis in one hundred years. By mid-April 2020, more than 80 percent of countries around the world had imposed strict containment and mitigation measures to control the spread of the disease. The economic fallout has been immense, with dire consequences for poverty and welfare, particularly in developing countries. This Brief first documents the global economic contraction and its potential impact on developing countries regarding macroeconomic performance, poverty rates, and incomes of the poor and vulnerable. It then argues that the pandemic crisis may hurt low- and middle-income countries disproportionately because most of them lack the resources and capacity to deal with a systemic shock of this nature. Their large informal sectors, limited fiscal space, and poor governance make developing countries particularly vulnerable to the pandemic and the measures to contain it. Next, the Brief reviews recent epidemiological and macroeconomic modelling and evidence on the costs and benefits of different mitigation and suppression strategies. It explores how these cost-benefit considerations vary across countries at different income levels. The Brief argues that, having more limited resources and capabilities but also younger populations, developing countries face different trade-offs in their fight against COVID-19 (coronavirus)than advanced countries do. For developing countries, the trade-off is not just between lives and the economy; rather, the challenge is preserving lives and avoiding crushed livelihoods. Different tradeoffs call for context-specific strategies. For countries with older populations and higher incomes, more radical suppression measures may be optimal; while for poorer, younger countries, more moderate measures may be best. Having different trade-offs, however, provides no grounds for complacency for developing countries. The Brief concludes that the goal of saving lives and livelihoods is possible with economic and public health policies tailored to the reality of developing countries. Since "smart" mitigation strategies (such as shielding the vulnerable and identifying and isolating the infected) pose substantial challenges for implementation, a combination of ingenuity for adaptation, renewed effort by national authorities, and support of the international community is needed. The lockdowns may be easing, but the fight against the pandemic has not been won yet. People and economies will remain vulnerable until a vaccine or treatment are developed. The challenge in the next few months will be to revive the economy while mitigating new waves of infection.Norman V Loayza (2020)

7) COVID-19 not only represents a worldwide public health emergency but has become an international economic crisis that could surpass the global financial crisis of 2008-09. Right now, containment and mitigation measures are necessary to limit the spread of the virus and save lives. However, they come at a cost, as shutdowns imply reducing economic activity. These human and economic costs are likely to be larger for developing countries, which generally have lower health care capacity, larger informal sectors, shallower financial markets, less fiscal space, and poorer governance. Policy makers will need to weigh carefully the effectiveness and socioeconomic consequences of containment and mitigation policies, responding to epidemiological evidence on how the virus spreads and trying to avoid unintended consequences. Economic policy in the short term should be focused on providing emergency relief to vulnerable populations and affected businesses. The short-term goal is not to stimulate the economywhich is impossible, given the supply-restricting containment measures, but rather to avoid mass layoffs and bankruptcies.Norman V Loayza, Steven Pennings (2020)

8) The virus that triggered a localized shock in China is now delivering a significant global shock. This study simulates the potential impact of COVID-19 on gross domestic product and trade, using a standard global computable general equilibrium model. It models the shock as underutilization of labor and capital, an increase in international trade costs, a drop in travel services, and a redirection of demand away from activities that require proximity between people. A baseline global pandemic scenario sees gross domestic product fall by 2 percent below the benchmark for the world, 2.5 percent for developing countries, and 1.8 percent for industrial countries. The declines are nearly 4 percent below the benchmark for the world, in an amplified pandemic scenario in which containment is assumed to take longer and which now seems more likely. The biggest negative shock is recorded in the output of domestic services affected by the pandemic, as well as in traded tourist services. Since the model does not capture fully the social isolation induced independent contraction in demand and the decline in investor confidence, the eventual economic impact may be different. This exercise is illustrative, because it is still too early to make an informed assessment of the full impact of the pandemic. But it does convey the likely extent of 
impending global economic pain, especially for developing countries and their potential need for assistance.Maliszewska (2020)

9) Multilateral financial institutions have pledged to do whatever it takes to enable emerging market and developing countries to fill a \$2.5 trillion financing gap to combat Covid-19 and subsequent economic crises. In this article, we present new datasets to track the extent to which multilateral financial institutions are meeting these goals, and conduct a preliminary assessment of progress to date. We find that the International Monetary Fund and the principal regional financial arrangements have made relatively trivial amounts of new financing available and have been slow to disburse the financing at their disposal. As of July 31, 2020, these institutions had committed $\$ 89.56$ billion in loans and $\$ 550$ million in currency swaps, totaling $\$ 90.11$ billion-just $12.6 \%$ of their current capacity. The new datasets allow scholars, policymakers, and civil society to continue to track these trends, and eventually examine the impact of such financing on health and development outcomes. Thomas Stubbs (2021)

10) With COVID-19 now spreading in developing countries, massive consequences on health and livelihoods are feared. Food security is the most important and crucial aspect of sustainable development. The agricultural sector forms the backbone of the economy and provides livelihood to a large section in developing countries. Therefore, the disruption in food security and the agricultural sector will have far-reaching impacts on these countries. Owing to the importance of these sectors, this paper performs a comprehensive assessment of the effect of COVID-19 on food security and agriculture. The research suggests coping and mitigation mechanisms that can be adopted to sustain livelihoods.Endashaw Workie (2020)

Conceptual model

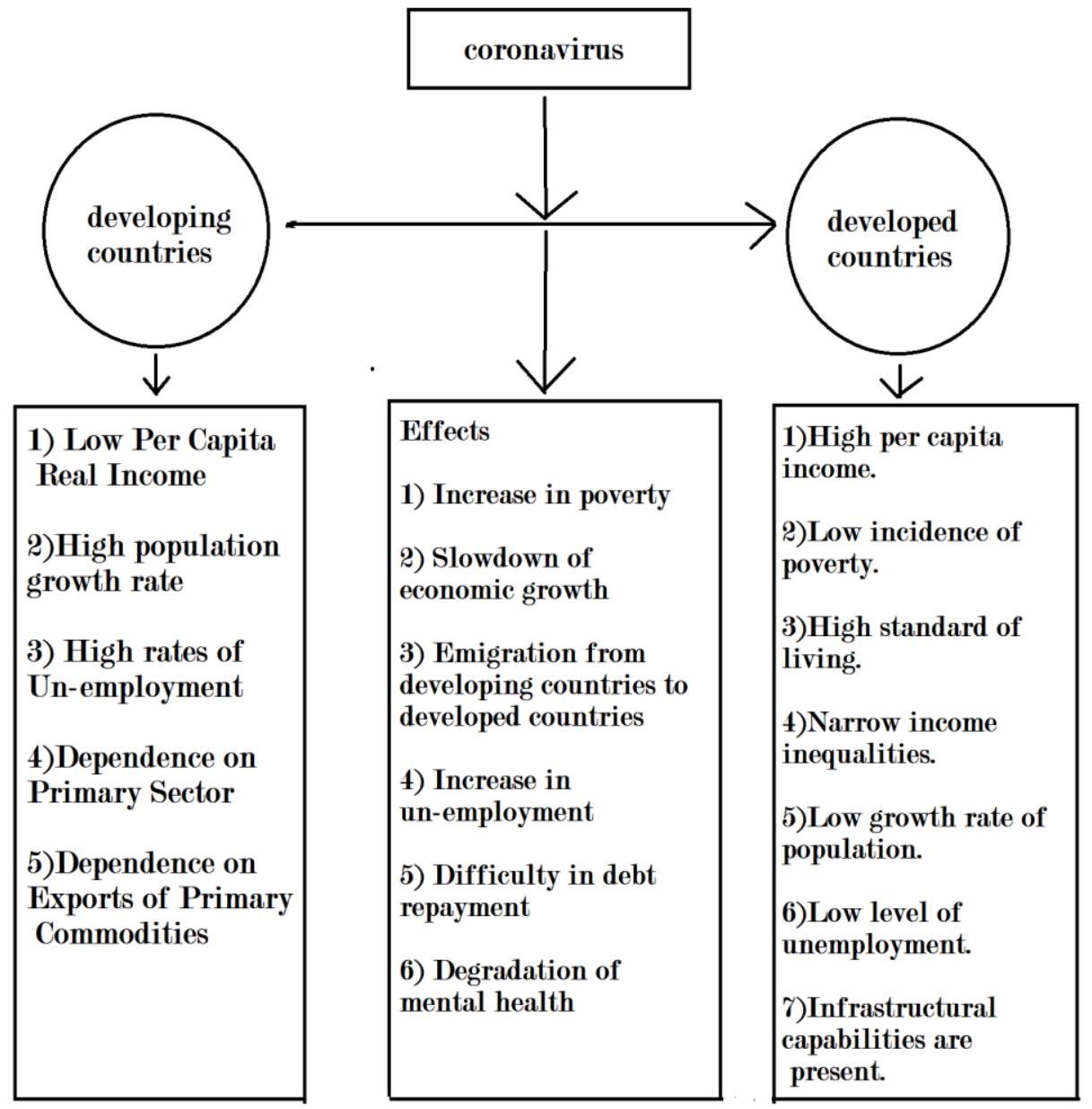

The conceptual model has three main components which are developing countries, coronavirus and developed countries. The developing countries have characteristics such as low per capita income, high population growth rate, high rates of un-employment, dependence on primary sector, dependence on exports of primary commodities. The developed countries have characteristics such as high per capita income, low incidence of poverty, high standard of 
living, Narrow income inequalities, low growth rate of population, low level of un-employment and availability of good infrastructure. Every developing country aims to become a developed country. The incidence of coronavirus has critically affected the goals of developing countries and has caused them many challenges. The effects which coronavirus has caused on developing countries are increase in poverty, slowdown of economic growth, Emigration from developing countries to developed countries, increase in un- employment, difficulty in debt repayment and degradation of mental health.

\section{Acknowledgements:-}

We would like to thank your teacher, ProfAbhishek Venkateshwarfor their input and feedbackinto the development of related concepts through scholarlydiscourse.

\section{References:-}

1)Rodela, T. T., Tasnim, S., Mazumder, H., Faizah, F., Sultana, A., \& Hossain, M. (2020, April Economic Impacts of Coronavirus Disease (COVID-19) in Developing Countries. https://doi.org/10.31235/osf.io/wygpk

2)Awadhesh Kumar Singh, AnoopMisra,Impact of COVID-19 and comorbidities on health and economics: Focus on developing countries and India,Diabetes\& Metabolic Syndrome: Clinical Research \& Reviews,(2020)

3)Thomas Reardon, Marc F Bellemare, David ZilbermanIFPRI book chapters (2020)

4) ) EndashawWorkie, JobyMackolil, Joan Nyika, SendhilRamadasCurrent Research in Environmental Sustainability (2020)

5) ) Titan M Alon, Minki Kim, David Lagakos, Mitchell VanVurenNational Bureau of Economic Research Working Paper Series (2020)

6) ) Costs and trade-offs in the fight against the Covid-19 pandemic: A developing country perspectiveNorman V Loayza World Bank(2020)

7) ) Macroeconomic policy in the time of COVID-19: A primer for developing countriesNorman V Loayza, Steven PenningsWorld bank(2020)

8) Maliszewska, Maryla and Mattoo, Aaditya and van der Mensbrugghe, Dominique, The Potential Impact of COVID-19 on GDP and Trade: A Preliminary Assessment (April 10, 2020). World Bank Policy Research Working Paper (2020)

9) Thomas Stubbs, William Kring, Christina Laskaridis, Alexander Kentikelenis, Kevin Gallagher, Whatever it takes? The global financial safety net, Covid-19, and developing countries, World Development,(2021)

10) EndashawWorkie, JobyMackolil, Joan Nyika, SendhilRamadas,Deciphering the impact of COVID-19 pandemic on food security, agriculture, and livelihoods: A review of the evidence from developing countries,Current Research in Environmental Sustainability(2020). 